\title{
Review of toxic glycosides in rangeland and pasture forages
}

\author{
WALTER MAJAK
}

Author is toxic plant biochemist, Agriculture and Agri-Food Canada Range Research Unit, Kamloops, B.C. V2B 8A9.

\begin{abstract}
Ruminants are a diverse group of mammals, both domestic and wild species, that exhibit microbial fermentation prior to gastrointestinal activity. During the digestive process, glycosides and other natural products are exposed to ruminal microorganisms and metabolised as substrates. Most compounds are converted into nutrients but some become toxic metabolites. At least 10 types of toxic glycosides occur in forage species. Glycosides are characterized by the presence of one or more sugars linked to the alcohol or thiol functions of the non-sugar portion of the molecule, which is called the aglycone. The biological activity of the glycoside is usually determined by the chemical nature of the aglycone. The aglycones are released by microbial enzymes and may undergo further enzymatic or non-enzymatic transformations to yield toxic metabolites that can be absorbed from the gastrointestinal tract. Microbial detoxification of the aglycone is also possible. Further biotransformation of the aglycone can occur in the liver. A review is presented on glycosides that are toxic to ruminants. The discussion covers aliphatic nitrocompounds, cyanogenic glycosides, cardiac glycosides, saponins, glucosinolates, diterpenoid glycosides, bracken glycosides, calcinogens, phenolic glycosides and ranunculin. Clinical signs of poisoning and treatment of livestock as well as management strategies for the prevention of poisoning are considered.
\end{abstract}

Key Words: poisonous plants, ruminants, cattle, rumen microbes

A diverse array of toxic glycosides occurs in higher plants, the most abundant of these being the glucosinolates (thioglycosides), the cyanogenic glycosides, the aliphatic nitrotoxins, and the cardiac glycosides. Glycosides are secondary plant products, many of which are recognized as active metabolites or allelochemicals that interact with other plants, microorganisms, insects, and animals. The roles of these compounds include the attraction of pollinators or seed dispersers and the repulsion or inhibition of herbivores and microorganisms (Rhoades 1979). Concentrations of toxic glycosides in plants can be affected significantly by physiological stress, such as water deficits or nutrient deficiencies. Other factors that may affect glycoside levels include stage of growth, accumulation in specific plant tissues, geographic or topographic location, and seasonal effects of soil and climate. This review will focus on the distribution of toxic glycosides in forage species and their mode of action in ruminants. Management strategies for the prevention and treatment of poisoning are also considered.

The author wishes to thank Ruth McDiarmid for her contributions in the preparation of this manuscript.

Manuscript accepted 27 Nov. 00
Resumen

Los rumiantes son un grupo diverso de mamíferos, que tanto especies domésticas como salvajes, que presentan fermentación microbiana antes de la actividad gastrointestinal. Durante el proceso digestivo los glicosidos y otros productos naturales son expuestos a los microorganismos ruminales y metabolizados como substratos. Muchos compuestos son convertidos en nutrientes pero algunos llegan a ser metabolitos tóxicos. Al menos 10 tipos de glicosidos tóxicos ocurren en las especies forrajeras. Los glicosidos son caracterizados por la presencia de uno o mas azúcares encadenados a las funciones alcohol o tiol de la porción noazúcar de la molécula, la cual es llamada aglicone. La actividad biológica del glicosido usualmente es determinada por la naturaleza química del aglicone. Los aglicones son liberados por las enzimas microbianas y pueden llegar sufrir mas transformaciones enzimáticas o no-enzimáticas para producir metabolitos tóxicos que pueden ser absorbidos del tracto gastrointestinal. La detoxificación microbiana del aglicone también es posible. Mas biotransformaciones del aglicone pueden ocurrir en el hígado. Se presenta una revisión de los glicosidos que son tóxicos para los rumiantes. La discusión cubre compuestos nitrogenados alifático, glicosidos cianogénicos, glicosidos cardíacos, saponinas, glucosinolatos, glicosidos diterpenoides, calcinógenos, glicosidos fenólicos y ranuculina. Se consideran los signos clínicos de envenenamiento y tratamiento del ganado, así como las estrategias de manejo para la prevención del envenenamiento.

Glycosides are conjugated alcohols formed when the alcoholic function of the aglycone adds to a sugar such as D-glucose. The biological activity of the glycosides is usually determined by the chemical nature of the aglycone, which is the non-sugar portion of the molecule. Glycosides most commonly occur as $O$-ß-D-glucosides. The glycosidic bond renders the glycosides innocuous through stabilization of the reactive aglycone (Majak and Benn 2000). In ruminants, an important feature of the digestive system is the occurrence of microbial fermentation in the rumen prior to gastrointestinal activity. About $50 \%$ of rumen bacteria possess B-glucosidase activity and the hydrolytic enzyme is also widely distributed among species of rumen ciliate protozoa and anaerobic fungi (Chesson and Forsberg 1988). Hydrolysis of the glycosidic bond is essential for the toxic expression of cyanogenic glycosides as well as aliphatic nitrotoxins such as miserotoxin. In monogastric animals the upper regions of the digestive tract are largely devoid of B-glucosidase activity; B-D-glucosides are not usually hydrolysed but are absorbed and excreted intact in the urine. Chemical inhibitors of B-glucosidase are known. These inhibitory compounds, both naturally-occurrring and synthetic, are structural analogues of glucose that bind tightly to the active 
site of the enzyme; however, if absorbed from the rumen they can be toxic to livestock (Nash et al. 1998).

Glucosinolates are $S$-ß-D-glucosides and thus not substrates for $O-B-\mathrm{D}$-glucosidase. Both ovine and bovine rumen fluids are devoid of myrosinase, the hydrolytic enzyme that releases the thiol aglycone (Majak 1992); however, glucosinolatecontaining plants all contain myrosinase. Thus the hydrolysis of glucosinolates in the rumen is contingent upon the activity of endogenous plant enzymes (Majak 1992, Majak et al. 1991). The thiol aglycone is unstable at physiologic $\mathrm{pH}$ and undergoes a non-enzymatic rearrangement to form isothiocyanates.

Hydrolysis of the glycosidic bond is not a prerequisite for the biological activity of polycyclic glycosides such as glycoalkaloids, saponins, and cardenolides. In fact, removal of the sugar units results in reduced activity with saponins and cardenolides, and loss of activity with glycoalkaloids (Majak and Benn 2000).

\section{Nitrocompounds}

Relatively few natural products contain the nitro group, but of those that do, 2 important sets correspond to sugar conjugates of 3-nitropropanol (NPOH) and 3nitropropionic acid (NPA). Although the latter are not glycosides, they often resemble them structurally and their mammalian toxicities are similar; it is for these reasons that they receive attention here (Majak and Pass 1989). The toxin karakin [1,2,6-tris$O$-(3-nitropropanoyl)-ß-D-glucopyranose] was the first nitrocompound to be isolated. The identification of miserotoxin (3-nitropropyl-ß-D-glucopyranoside) followed the observation that Astragalus miser var. oblongifolius (Rydb.) Cronq. was responsible for losses of stock on rangelands of the western United States. Glucose esters of NPA such as karakin are found in the Leguminosae (Astragalus, Coronilla, Indigofera, and Lotus) and miserotoxin occurs in numerous species of Astragalus (milkvetch). It has become well established that NPA is the lethal metabolite formed in the biotransformation of nitropropyl glycosides or nitropropanoyl glucose esters. The esters yield NPA directly upon hydrolysis, but the bioactivation of the glycosides requires a second metabolic step; after hydrolytic release of the aglycone, NPOH is oxidized to NPA, probably by liver alcohol dehydrogenase (Majak and Pass 1989). The NPA is a potent inhibitor of Krebs (tricarboxylic acid) cycle enzymes essential to respiration and, more recently it has been implicated as a causative agent of neuronal degeneration in mammals (Alexi et al. 1998).

The major clinical signs in the acute syndrome include incoordination, distress, labored breathing, cyanosis, muscular weakness, and collapse, with death occurring from a few hours to a day after ingestion of the toxin. In chronic poisoning, the animals lose weight and develop respiratory distress, a poor hair coat, hind limb paresis progressing to paralysis, and a nasal discharge. Early signs of poisoning in cattle under field conditions include frothy salivation, stupefaction, diarrhea and labored breathing (Majak and Pass 1989, Maricle et al. 1996). When forced to move as part of a group they exhibit signs of incoordination and will lag behind. Recent field observations do not support the concept of livestock addiction to $\mathrm{NPOH}$-containing plants (Majak et al. 1996). No specific antidote is available for the treatment of livestock poisoned with aliphatic nitrotoxins but dietary protein supplements can enhance the activity of unique rumen bacteria capable of NPOH detoxification (Majak et al. 1996). These bacteria reduce the nitro group to the much less toxic amino group (Anderson et al. 1998).

\section{Cyanogenic glycosides}

In plants, cyanogenesis or the release of $\mathrm{HCN}$ is associated with the disruption of cells followed by autolysis as the glycosides are exposed to endogenous plant enzymes. The resulting aglycones are unstable cyanohydrins. At physiologic $\mathrm{pH}$ they undergo a rapid dissociation to yield $\mathrm{HCN}$ and either an aldehyde (e.g.benzaldehyde in the case of prunasin) or a ketone (e.g. acetone, in the case of linamarin). The dissociation is a $\mathrm{pH}$-dependent reaction with higher rates of $\mathrm{HCN}$ formation occurring at a $\mathrm{pH}$ greater than 6 and much slower rates at $\mathrm{pH}$ 5-6. Cattle should be least susceptible to poisoning during feeding and digestion when the $\mathrm{pH}$ of rumen fluid is depressed and most susceptible after a 24 hour fast (Majak et al. 1990).

The HCN is extremely toxic because it blocks aerobic cellular respiration. The toxic effect is mainly attributed to inhibition of cytochrome oxidase but other metabolic processes may also be affected. Physiologically, $\mathrm{HCN}$ poisoning results in histotoxic anoxia with the initial manifestation of hyperpnea, followed by dyspnea, and then convulsive seizures. Clinical signs of poisoning with cyanogenic glycosides develop at a much slower rate than they do for sodium cyanide, which has been attributed to the slower release of HCN from the glycoside. The delayed release of $\mathrm{HCN}$ permits a greater degree of detoxification through thiocyanate formation. Clinical signs of subacute and acute poisoning in cattle resulting from administration of prunasin include tachycardia, hyperpnea, recumbency, increased pinkness of the mucous membranes, and tonic convulsive contractions (Majak et al. 1980). The classic nitrite-thiosulfate treatment is still the preferred therapeutic method, especially if it is supplemented with oxygen (Majak et al. 1980, Way 1984).

The distribution of cyanogenic glycosides in the plant kingdom has been extensively reviewed (Poulton 1983). The Leguminosae (Trifolium spp.), Rosaceae (Prunus spp. and Amelanchier spp.), and Juncaginaceae (Triglochin spp.) have been particularly rich sources where the glycosides occur in white clover, wild cherry, serviceberry and arrowgrass, respectively.

\section{Cardiac glycosides}

As a consequence of their powerful effect on the heart, preparations containing cardiac glycosides have a long history as medicinals and poisons. Probably most famous in the Western world is the introduction of digitalis, an extract of Digitalis purpurea L. (foxglove), for the treatment of heart disease, but similar usage of Scilla maritima L. (squill; sea onion) dates back to ancient civilizations. Cardiac glycosides are characterized by a steroidal aglycone which is 1 of 2 structural types: cardenolides, such as digitalin, or bufadienolides such as scilleroside. Both cardenolides and bufadienolides are plant products, common particularly in the Asclepiadaceae (milkweeds), Apocynaceae, and Liliaceae. Dogbane (Apocynum cannabinum L.) contains high concentrations of the cardenolide cymarin $(0.1 \%$ on a dry wt basis, W. Majak unpublished results). Bufadienolides are also associated with the poison glands of toads (Joubert 1989, Majak and Benn 2000).

It is generally accepted that the $\mathrm{Na}^{+}$$\mathrm{K}^{+}$-adenosinetriphosphatase in cardiac muscle is the major pharmacological receptor of cardiac glycosides. Inhibition by cardenolides such as ouabain and digitoxin affects intracellular electrolyte concentrations, resulting in more forceful contractions of the myocardium. Therapeutic at medicinal doses for the treatment of congestive heart failure in humans, they are toxic to domestic herbivores when consumed at the natural concentrations in plants. Sub-acute to acute signs of poison- 
ing in cattle and sheep include restlessness, dyspnea, ruminal atony, frequent urination and defecation, tachycardia, arrhythmia, and ventricular fibrillation. The closely related bufadienolides produced similar signs of poisoning in cattle. All cardiac glycosides may be regarded as highly toxic (Joubert 1989, Majak and Benn 2000).

Various treatments for cardiac glycoside poisoning in humans and livestock have been reviewed (Joubert 1989); these include the use of activated charcoal, potassium chloride, atropine, digoxin-specific antibodies, ß-adrenergic blocking agents, procainamide and phenytoin.

\section{Saponins}

Saponins are glycosidic conjugates of triterpenes. The name derives from their soap like property of forming stable foams when shaken in dilute aqueous solutions. They are also noted for their ability to hemolyse red blood cells, even at high dilution. Historically, Medicago sativa L. (alfalfa) and Dioscorea species (yams) have been recognized as rich in saponins but they are widely distributed throughout the plant kingdom, to the point that they appear to be ubiquitous. In spite of their wide distribution, only a small number of species contain saponins that are toxic to mammals (Cheeke 1998). This has been attributed to their negligible degree of absorption from the gastrointestinal tract. There appears to be a growing list of saponin-containing forages that are implicated in hepatogenous photosensitization of livestock, with sapogenins being detected as crystals in obstructed bile ducts (Cheeke 1998).

The toxic saponin effect is usually initiated by interaction with mucosal membranes, causing permeability changes or loss of membrane-bound enzymes (Oakenfull and Sidhu 1989). Lysis of the mucosal cell membranes results in intestinal lesions and severe gastroenteritis. Under these conditions, saponins may be absorbed from the gastrointestinal tract and produce systemic effects such as liver damage, respiratory failure, violent convulsions, and coma. The ability of saponins to disrupt and lyse cell membranes enhances their activity when given intravenously. Saponins are also antinutritional factors in swine and poultry feeds such as alfalfa (Cheeke 1998). The adverse effects of saponins have been reversed by the inclusion of dietary cholesterol, presumably because saponins form insoluble complexes with cholesterol or they perturb cholesterol-containing micelles (Oakenfull and Sidhu 1989).

\section{Glucosinolates}

The glucosinolates, precursors of organic isothiocyanates (mustard oils) are mainly constituents of members of the Brassicaceae (Cruciferae), but they are also found in other smaller tropical families. Some glucosinolate breakdown products are goitrogenic agents that cause hyperplasia and hypertrophy of the thyroid gland. Two types of goitrogens are derived from glucosinolates, which act on the thyroid gland in different ways. The thiocyanate ion, the less potent of the 2 , is derived from the breakdown of alkyl isothiocyanates or indole isothiocyanates. It inhibits uptake of inorganic iodide by the thyroid gland, apparently in a competitive way since the inhibition can be reversed with iodide supplements. The cyclic thiouracils, such as goitrin, are derived from the hydrolysis of glucosinolates containing a B-hydroxyl substituent. Goitrin and other thiouracil analogues interfere with tyrosine iodination and the coupling reactions that sythesize thyroxine or triiodothyronine, and their effects cannot be reversed. Antithyroid drugs are available for the treatment of hyperthyroidism; these include methimazole, propylthiouracil, and such other antithyroid drugs as the sulfonamides, amphenone, and chlorpromazine (Fenwick et al. 1989).

Ingestion of mustard (Brassica spp.) seeds by cattle and the release of mustard oils can result in lesions in the gastrointestinal tract including profuse edema of the forestomachs and abomasum and mucosal necrosis and hemorrhage of the cecum and colon. In addition to the isothiocyanates, episulfides, thiocyanates and nitriles also are produced during autolysis of glucosinolates. Allylthiocyanate is formed during stinkweed (Thlaspi arvense L.) autolysis, and the irritant oil may cause severe gastric distress. Nitriles having pancreatotoxic and nephrotoxic effects can be generated during the autolysis of Brassica species and other crucifers (Majak 1992, Majak and Benn 2000).

\section{Diterpenoid glycosides}

The 1970-1980 decade saw the isolation and characterization of hypoglycemic agents from species of the Compositae such as Atractylis, Xanthium (cocklebur), and Wedelia. The toxic diterpenoid glycosides from these sources were respectively named atractyloside, carboxyatractyloside, and wedeloside. These glycosides can block the mitochondrial ADP/ATP energy-carrier system and the resultant cellular dysfunction is characterized by inhibited oxidative phosphorylation, accel- erated anaerobic glycolysis, lactate production, and glycogenolysis. Clinical signs of poisoning in livestock include acute depression, weakness, and convulsions, and the accompanying pathologic changes include nephrosis, gastric irritation, hepatic necrosis, and marked hypoglycemia (Cole et al. 1989). A current and comprehensive review on the biochemistry and toxicology of atractylosides is available (Obatomi and Bach 1998).

\section{Bracken glycosides}

Poisoning of cattle by bracken (species of the fern Pteridium) had been suspected for many years, but the first report of lesions in experimental animals on a diet including bracken did not appear until 1965 , when rats were found to develop cancers. Another 18 years passed before the carcinogenic agent was isolated and identified as the sesquiterpene glycoside ptaquiloside. Ptaquiloside and several analogues have since been isolated from other ferns. The prominent feature of "bracken poisoning" in cattle is depressed bone marrow activity that results in leukopenia, thrombocytopenia, and hemorrhages of the urinary bladder that give rise to hematuria. Ptaquiloside is apparently transferred to cows' milk, and could pose a human health hazard (Hirono 1986, 1989). Bracken also contains the enzyme thiaminase, which can induce polioencephalomalacia in monogastric animals and ruminants (Chick et al. 1989, Cheeke 1998).

\section{Calcinogenic glycosides}

Pathological calcinogenesis, calcinosis, refers to the deposition of calcium salts in soft tissues. A causative link between the ingestion of Solanum glaucophyllum Desf. (S. malacoxylon Sm.) and the incidence of a calcinotic disease of livestock in Argentina and Brazil was suspected for some time, as it was for Cestrum diurnum L. in Florida and Trisetum flavescens (L.) Beauv. in the European alps. An isolation of the biologically active fraction from $S$. glaucophyllum, treated with B-glucosidase, released calcitriol $(1 \alpha, 25$-dihydroxy vita$\min \mathrm{D}_{3}$ ). Subsequently, vitamin $\mathrm{D}_{3}$ and its 25-hydroxy and 1 $\alpha, 24,25$-trihydroxy derivatives were also found. The calcinogenic glycosides of $C$. diurnum and $T$. flavescens also proved to be derivatives of vitamin $\mathrm{D}_{3}$ (Weissenberg 1989, Majak and Benn 2000).

Dietary or endogenous vitamin $\mathrm{D}_{3}$ is hydroxylated at $\mathrm{C}_{25}$ and stored in the liver. It is activated further in the kidney by hydroxylation at $C_{1}$. This active form is required for the synthesis of calcium 
carrier proteins involved in the transport of the cation from the intestine under conditions of calcium deprivation. It is this dihydroxylated active form of vitamin $\mathrm{D}_{3}$ that occurs in glycosidic forms in Solanum glaucophyllum and Cestrum diurnum. Consequently, consumption of this exogenous form of vitamin $\mathrm{D}_{3}$ results in excess absorption of calcium and phosphate from the intestine leading to calcification of soft tissues. Symptoms of calcinogenesis in both livestock and laboratory animals have been reviewed comprehensively (Weissenberg 1989).

\section{Phenolic glycosides}

A very large number of phenolic glycosides have been isolated from plants, and their aglycones exhibit considerable structural diversity and biological activity. There is evidence to suggest that the phenolic glycosides of plants provide a defense against herbivorous insects but only a few are regarded as dangerously toxic to mammals. In most cases, the toxic agents have been identified as the phenolic aglycones. Classic examples include the isoflavonoid daidzein and formononetin, found in subterranean clover (Trifolium subterraneum L.), and coumestrol, which occurs in alfalfa (Medicago sativa L.). Both of these phytoestrogens induce abortions in sheep. Reproductive problems were first encountered over 50 years ago with the establishment of subterranean clover on pastures in western Australia. A dramatic decrease in the fertility of sheep was noted. The failure to conceive was attributed to a change in the viscosity of the cervical mucus and the resultant impaired passage of spermatozoa. The condition was accompanied by cystic glandular hyperplasia of the cervix and uterus and lactation in nonpregnant ewes and wethers. Clinical signs of reproductive disorders diminished with the introduction of new cultivars of clover that were low in formononetin, but a temporary infertility still prevailed among ewes exposed to phytoestrogen-containing pastures. Reproductive disorders on alfalfa pastures usually are associated with increases in coumestrol concentrations resulting from fungal infections, often referred to as a phytoalexin response. Coumestrol and related coumestans decrease the ovulation rate in ewes. There is no satisfactory explanation for the reduced susceptibility of cattle as compared to sheep to the effects of phytoestrogen-containing pastures. Immunological approaches for the prevention of phytoestrogenic disorders have been partially successful under experimental and field conditions (Adams 1989).

Melilotoside, coumarinic acid B-D-glucoside, is the bound form of coumarin that can be found in high concentrations in sweet clover (Melilotus spp.). Sweet clover poisoning is associated with moldy hay or silage where enzymes of fungal origin metabolize coumarin to dicoumarol, a potent anticoagulant. Dicoumarol interferes with the synthesis of thrombin, which is required for fibrin formation and blood clotting. Signs of poisoning in cattle include lethargy, anemia, and the development of subdermal swelling in reponse to internal hemorrhaging, which is the cause of death (Kingsbury 1964). The induced deficiency can be ameliorated with increased vitamin $\mathrm{K}$, especially vitamin $\mathrm{K}_{1}$ given intramuscularly (Alstad et al. 1985). "Low coumarin" cultivars of sweet clover are available but "high coumarin" Melilotus persists in pastures and as a weed.

\section{Ranunculin}

The recognition that chewing the fresh leaves or blossoms of buttercups released a vesicant substance must be prehistoric. The toxin has been identified as the unsaturated $\Upsilon$-lactone protoanemonin (5-methylene-2-oxodihydrofuran), but the storage form of this unstable compound remained in doubt until recently when the parent BD-glucoside was re-isolated by different extraction protocols and identified as ranunculin (Bai et al. 1996). Ingestion of the plant material can cause gastric distress, including irritation of the digestive tract, abdominal pain, and diarrhea. When Ceratocephalus testiculatus Crantz. (bur buttercup) was given to sheep, clinical signs of poisoning included weakness, depression, tachycardia, dyspnea, anorexia, diarrhea, and sometimes fever (Olsen et al. 1983). Ranunculin has been obtained from numerous species of the buttercup family (Ranunculaceae) (Bai et al. 1996). The purified glycoside is a substrate for Bglucosidase which can release the aglycone; however, during the autolysis of ranunculin-containing forages, protoanemonin is released and not the aglycone. Two competing reactions occurred in rumen fluid when Ranunculus cymbalaria Pursh. was incubated in vitro: microbial hydrolases yielded the aglycone and the endogenous plant enzyme yielded protoanemonin (Majak et al., unpublished data). This is another example where the release of the toxic metabolite, protoanemonin, is contingent upon the specific activity of endogenous plant enzyme.

\section{Cycasin}

Two distinct field diseases have been recognized in livestock poisoning by cycads and zamias. One is a neurotoxic syndrome characterized by ataxia and permanent weakness of the hindquarters. A rare amino acid was implicated but others have excluded this agent (Charlton et al. 1992). The second syndrome is a hepatic and gastrointestinal disease attributed to cycasin, methylazoxymethanol-ß-D-glucoside (Hooper 1983). Acute cycasin toxicity in sheep and cattle is characterized by hepatitis, gastroenteritis, hemorrhages, and liver cirrhosis. In chronic poisoning, animals lose appetite and develop mild liver cirrhosis and nephrosis. The labile aglycone is the lethal metabolite.

In summary, 11 classes of toxic glycosides have been examined in this review. Bioactivation and toxicity of the glycosides mainly depend on 1) the rate of release of the aglycone by rumen microbes, 2) the rate of detoxification of the aglycone, and 3) the degree of absorption of the aglycone from the gastrointestinal tract. Plant enzymes may also be involved in the mode of action of toxic glycosides. Clearly, these results indicate that the rumen ecosystem is the first line of defense and it should be further exploited for pathways of detoxification.

\section{Literature Cited}

Adams, N.R. 1989. Phytoestrogens, p. 23-51. In: P.R. Cheeke (ed.) Toxicants of Plant Origin, Vol. IV, Phenolics. CRC Press Inc., Boca Raton, Fla.

Alexi, A., P.E. Hughes, R.L.M. Faull, and C.E. Williams. 1998. 3-Nitropropionic acid's lethal triplet: cooperative pathways of neurodegeneration. NeuroReport 9:57-64.

Alstad, A.D., H.H. Caspar, and L.J. Johnson. 1985. Vitamin $K$ treatment of sweet clover poisoning in calves. J. Amer. Vet. Med. Assoc. 187:729-731.

Anderson, R.C., W. Majak, M.A. Rasmussen and M.J. Allison. 1998. Detoxification potential of a new species of ruminal bacteria that metabolize nitrate and naturally occurring nitrotoxins, p. 154-158. In: Tam Garland and A. Catherine Barr (eds.), Toxic plants and other natural toxicants. CAB International.

Bai, Y., M.H. Benn, W. Majak, and R. McDiarmid. 1996. Extraction and HPLC determination of ranunculin in species of the buttercup family. J. Agr. Food Chem. 44:2235-2238.

Charlton, T.S., A.M. Marini, S.P. Markey, K. Norstog, and M.W. Duncan. 1992. Quantification of the neurotoxin 2-amino-3-(methylamino)-propanoic acid (BMAA) in Cycadales. Phytochemistry 31:3429-3432. 
Cheeke, Peter R. 1998. Natural toxicants in feeds, forages, and poisonous plants. Second Edition. Interstate Publishers Inc., Danville, Ill.

Chesson, A. and C.W. Forsberg. 1988. Polysaccharide degradation by rumen microorganisms, p. 251-284. In: P.N. Hobson (ed.), The rumen microbial ecosystem. Elsevier Appl. Sci., London and New York.

Chick, B.F., B.V. McCleary, and R.J. Becket. 1989. Thiaminases, p. 73-91. In P.R. Cheeke (ed.), Toxicants of plant origin, Vol. III, Proteins and amino acids. CRC Press, Inc., Boca Raton, Fla.

Cole, R.J., H.G. Cutler, and B.P. Stuart. 1989. Carboxyatractyloside, p. 253-263. In P.R. Cheeke (ed.), Toxicants of plant origin, Vol. II, Glycosides. CRC Press Inc., Boca Raton, Fla.

Fenwick, G.R., R.K. Heaney, and R. Mawson. 1989. Glucosinolates, p. 1-41. In: P.R. Cheeke (ed.), Toxicants of plant origin, Vol. II, Glycosides. CRC Press Inc., Boca Raton, Fla.

Hirono, I. 1986. Carcinogenic principles isolated from bracken fern. CRC Crit. Rev. Toxicol. 17:1-22.

Hirono, I. 1989. Carcinogenic bracken glycosides, p. 239-251. In: P.R. Cheeke (ed.), Toxicants of Plant Origin, Vol. II, Glycosides. CRC Press Inc., Boca Raton, Fla.

Hooper, P.T. 1983. Cycad poisoning, p. 463-471. In: R.F. Keeler and A.T. Tu (eds.), Handbook of natural toxins, Vol. I, Plant and fungal toxins. Marcel Dekker Inc., New York, N.Y

Joubert, J.P.J. 1989. Cardiac glycosides, p. 61-69. In: P.R. Cheeke (ed.), Toxicants of plant origin, Vol. II, Glycosides. CRC Press Inc., Boca Raton, Fla.
Kingsbury, J.M. 1964. Poisonous plants of the United States and Canada. Prentice Hall Inc., Englewood Cliffs, N.J.

Majak, W. 1992. Biotransformation of toxic glycosides by ruminal microorganisms, $\mathrm{p}$. 86-103. In: R.F. Keeler, N.B. Mandava, and A.T. Tu (eds.), Natural toxins: toxicology, chemistry and safety. Alaken Inc., Fort Collins, Colo.

Majak, W. and M.H. Benn. 2000. Glycosides, p. 299-349. In: Y.H. Hui, R.A. Smith, D.G. Spoerke (eds.), Foodborne disease handbook, Vol. 3, Plant Toxicants. Marcel Dekker Inc., New York, N.Y.

Majak, W. and M.A. Pass, 1989. Aliphatic nitrocompounds, p. 143-159. In: P.R. Cheeke (ed.), Toxicants of plant origin, Vol. II, Glycosides. CRC Press Inc., Boca Raton, Fla.

Majak, W., R.E. McDiarmid, M.H. Benn, and W.D. Willms. 1991. Autolysis of Thlaspi arvense in bovine rumen fluid. Phytochemistry 30:127-129.

Majak, W., R.E. McDiarmid, J.W. Hall, and K.-J. Cheng. 1990. Factors that determine rates of cyanogenesis in bovine ruminal fluid in vitro. J. Anim. Sci. 68:1648-1655.

Majak, W., T. Udenberg, L.J. Clark, and A. McLean. 1980. Toxicity of saskatoon serviceberry to cattle. Can. Vet. J. 21:74-76.

Majak, W., L. Stroesser, J.W. Hall, D.A. Quinton, and H.E. Douwes. 1996. Seasonal grazing of Columbia milkvetch by cattle on rangelands in British Columbia. J. Range Manage. 49:223-227.

Maricle, B., J. Tobey, W. Majak, and J.W. Hall. 1996. Evaluation of clinicopathological parameters in cattle grazing timber milkvetch. Can. Vet. J. 37:153-156.
Nash, R.J., A.A. Watson, A.L. Winters, G.W.J. Fleet, M.R. Wormald, S. Dealler, E. Lees, N. Asano, and R.J. Molyneux. 1998. Glycosidase inhibitors in British plants as causes of livestock disorders, p. 276-284. In: Tam Garland and A. Catherine Barr (eds.), Toxic plants and other natural toxicants. CAB International.

Oakenfull, D. and G.S. Sidhu. 1989. Saponins, p. 97-142. In: P.R. Cheeke (ed.), Toxicants of plant origin, Vol. II, Glycosides. CRC Press Inc., Boca Raton, Fla.

Obatomi, D.K. and P.H. Bach. 1998. Biochemistry and toxicology of the diterpenoid glycoside atractyloside. Food Chem. Toxicol. 36:335-346.

Olsen, J.D., T.E. Anderson, J.C. Murphy and G. Madsen. 1983. Bur buttercup poisoning of sheep. J. Amer. Vet. Med. Assoc. 183:538-543.

Poulton, J.E. 1983. Cyanogenic compounds in plants and their toxic effects, p. 117-157. In: Richard F. Keeler and Anthony T. Tu (eds.), Handbook of natural toxins, Vol. 1, Plant and fungal toxins. Marcel Dekker Inc., New York, N.Y.

Rhoades, D.F. 1979. Evolution of plant chemical defense against herbivores, p. 3-54. In: Gerald A. Rosenthal and Daniel H. Janzen (eds.), Herbivores, Their interaction with secondary plant metabolites. Academic Press, New York, N.Y.

Way, J.L. 1984. Cyanide intoxication and its mechanism of antagonism. Ann. Rev. Pharmacol. Toxicol. 24:451-481.

Weissenberg, M. 1989. Calcinogenic glycosides, p. 201-238. In: P.R. Cheeke (ed.), Toxicants of plant origin, Vol. II, Glycosides. CRC Press Inc., Boca Raton, Fla. 